\title{
Particularities of Coronary Artery Disease in the Elderly in a Black African Country in the South of the Sahara (Senegal)
}

\author{
Mingou JS ${ }^{1 *}$, Ndiaye MB ${ }^{1}$, Aw F ${ }^{1}$, Sarr SA ${ }^{1}$, Dioum $\mathrm{M}^{2}$, Ravaoavy $\mathrm{H}^{1}$, Kouame MIM${ }^{1}$, Ndao SCT ${ }^{1}$, Ngaindé $\mathrm{AA}^{3}$, \\ Bodian $\mathbf{M}^{1}$, Diack $\mathrm{B}^{3}$,Diao $\mathbf{M}^{1}$, Kane $\mathrm{A}^{4}$ and Ba $\mathrm{SA}^{1}$
}

${ }^{1}$ Department of Cardiology, Aristide Le Dantec Hospital University, Senegal

${ }^{2}$ Department of Cardiology, FANN Hospital University, Senegal

${ }^{3}$ Department of Cardiology, HOGGY Hospital University, Senegal

${ }^{4}$ Department of Cardiology, Dalal Jamm Hospital, Senegal

Submission: March 04, 2017; Published: July 05, 2017

*Corresponding author: Mingou JS, Department of Cardiology, Aristide Le Dantec Hospital University, Dakar Senegal, Email: mingoujoseph@mail.com

\begin{abstract}
Due to the demographic progression of our societies and the increasing prevalence with age of coronary artery disease, we will increasingly face the treatment of acute coronary syndrome in elderly patients ( $>70$ years). Very little data has been published in Africa, particularly in the South of the Sahara. This series shows the severity of coronary lesions in subjects aged over 70 years admitted to the cardiology department of the Aristide Le Dantec hospital and the interest of the invasive strategy in this population.
\end{abstract}

Introduction: Coronary artery disease in the elderly is often more diffuse and severe. The objective of our study was to describe the results of coronary angiography and angioplasty in the elderly in Senegal.

Methodology: A monocentric, retrospective and descriptive study over a period of 39 months from 1 May 2013 to 31 July 2016 was carried out within the cardiology department of the teaching hospital: Aristide Le Dantec in Dakar. Were included all patients who had coronary angiography with a complete clinical record.

Results: A total of 380 records were collected during the study period. The prevalence of subjects over 70 years of age was $12.7 \%$ (n =38). The mean age was $74.37+/-4.1$ years. The sex ratio was 2.35 in favor of men. The main risk factors were hypertension $(51 \%)$, sedentary lifestyle (46.8\%) and diabetes (27.7\%). The main indications were SCA ST+ in 14 cases (29.8\%) and the angina of effort in 11 cases (23.4\%). Nearly half (51.1\%) of the patients had angina pain at discharge. LV systolic dysfunction was noted in 21 patients (58.3\%). Nine (19.1\%) patients were able to benefit from thrombolysis. Coronary angiography was programmed in most of our patients (80.9\%), the right femoral approach was preferred (70.2\%). The average duration of the procedure was $66.24 \mathrm{~min}$.

At the angiogram, a mean Syntax score was high in 4 patients (8.5\%) in subjects over 70 years, with diffuse coronary involvement both in the proximal but also distal segments; and with many more coronary occlusions within this population group. Coronary angioplasty with stent placement was proposed in 13 patients (27.7\%), with almost as many active stents as bare stents and a good result and TIMI 3 streams in $84.6 \%$. Very few incidents and complications related to angioplasty were noted.

Conclusion: Our work confirms the greater severity of coronary lesions in the elderly black African. Coronary angioplasty is achievable with a high success rate.

Keywords: Coronary angiography; Angioplasty; Dakar; Coronary heart disease; Elderly; Black africa; Senegal

\section{Introduction}

With the continuous increase in life expectancy at birth, the proportion of elderly people over 70 years of age has increased considerably in African countries. The coronary disease of the elderly is known to be very diffuse and more severe than that of the young subject (ref). So far, very little literature has been 
published in Africa, particularly in sub-Saharan Africa, in this ever-increasing population.

Age is a risk factor in the development of coronary artery disease and the aging of the population generates an increase in the proportion of elderly coronary patients. Age is the most powerful independent factor of intra-hospital mortality and of medium-term morbidity and mortality in cases of myocardial infarction [1]. The advent of coronary angiography and coronary angioplasty has altered the prognosis of older coronary arteries.

Through this retrospective study carried out at the Cardiology Department of the Aristide Le Dantec University Hospital in Dakar, Senegal, we wanted to study the peculiarities of coronary artery disease in patients over 70 years of age and more specifically the epidemiological profile of these elderly patients admitted In the catheterization room, indications, procedure of examination, results as well as angioplasty.

\section{Patients and Methods}

The catheter labor of the teaching hospital Aristide Le Dantec began its activities on first of May 2013. This study took into account all coronary angiography procedures and coronary percutaneous angioplasty performed in our department in patients over 70 years of age over a period of 39 months between May 1st and 2013 and July 31st, 2016, were included.

Clinical admission data, hospital outcomes and complications were collected from hospital records and patient records. Data on coronary angiography and coronary angioplasty procedures were collected from a coronary angiography report. In addition,

Table 1: Characteristics and clinical data of the population.

\begin{tabular}{|c|c|c|c|}
\hline Variables & $\begin{array}{c}\text { Patients over } 70 \text { years old } N \\
(\%)\end{array}$ & $\begin{array}{c}\text { Patients under70 years old } N \\
(\%)\end{array}$ & $P$ value \\
\hline Men & $33(70,2 \%)$ & $255(76,6 \%)$ & NS \\
\hline Women & $14(29,8 \%)$ & $78(23,4 \%)$ & NS \\
\hline Sex ratio $(H / F)$ & 2,35 & 3,26 & NS \\
\hline Average age (ans) & 74,37 & 57,51 & NS \\
\hline \multicolumn{4}{|c|}{ Cardio-vascular Risk Factors } \\
\hline High blood pressure & $24(51,1 \%)$ & $157(47,1 \%)$ & NS \\
\hline Dyslipidemia & $7(14,9 \%)$ & $64(19,2 \%)$ & NS \\
\hline Over weight & $14(29,8 \%)$ & $82(24,6 \%)$ & NS \\
\hline Diabetes & $13(27,7 \%)$ & $102(30,6 \%)$ & NS \\
\hline Smoking & $8(17 \%)$ & $85(25,5 \%)$ & NS \\
\hline Sedentariness & $22(46,8 \%)$ & $98(29,4 \%)$ & 0,02 \\
\hline Heredity & $3(6,4 \%)$ & $39(11,7 \%)$ & NS \\
\hline Known with coronary disease & $10(21,2 \%$ & $87(26,1 \%)$ & NS \\
\hline \multicolumn{4}{|c|}{ Onset Symtpoms } \\
\hline Chest pain & $24(51,1 \%)$ & $137(41,1 \%)$ & NS \\
\hline Dyspnea & $3(6,4 \%)$ & $18(5,4 \%)$ & NS \\
\hline Asymptomatic & $20(42,6 \%)$ & $175(52,6 \%)$ & NS \\
\hline Reduced ejection fraction & $21(58,3 \%)$ & $85(36,3 \%)$ & 0,02 \\
\hline
\end{tabular}

each film of coronary angiography and/or coronary angioplasty has been re-read exhaustively by 2 experienced operators.

An occlusive lesion is defined by a stenosis of more than $90 \%$ of the arterial lumen, a lesion is described as tight if the stenosis is between 70 and $90 \%$, significant between 50 and $70 \%$. The lesion is intermediate if the stenosis is $50 \%$ and not significant if the stenosis is less than $50 \%$. Patients were classified according to the number of coronary arteries affected by monotron- cular (epicardial vessels), two-vessel (two epicardial vessels) and three-tric cated (three epicardial vessels).

Depending on the complexity the lesions were classified as type A, B (B1, B2) and C according to the ACC/AHA classification [2]. The primary success of coronary angioplasty was defined as residual stenosis $<50 \%$ and TIMI 3 (Thrombolysis in Myocardial Infarction). By convention, arterial reperfusion was defined by the TIMI grades established in the first clinical trials of thrombolysis in myocardial infarction. The data were analyzed using the software SPSS 20.0 software. A value of $p<0.05$ is considered statistically significant.

\section{Results}

During the study period, 380 acts of coronary angiography were performed in the center. Of these, $12.7 \%$ of coronary angiography occurred in 38 patients aged over 75 years. Patient characteristics and clinical data are detailed in Table 1 . The mean age of patients was 74.37 years (range: 71 to 89 years), with a male predominance $(70.2 \%)$. The prevalence of hypertension was high $(51.1 \%)$ and diabetes $(27.7 \%)$. The sedentary rate was $46.8 \%$. 


\section{Journal of Cardiology \& Cardiovascular Therapy}

\begin{tabular}{|c|c|c|c|}
\hline \multicolumn{5}{|c|}{ Indications for Angiography } \\
\hline STEMI & $14(29,8 \%)$ & $90(27 \%)$ & NS \\
\hline NON STEMI & $3(6,4 \%)$ & $11(3,3 \%)$ & NS \\
\hline Unstable angina & $9(19,1 \%)$ & $73(21,9 \%)$ & NS \\
\hline Stable angina & $11(23,4 \%)$ & $78(23,4 \%)$ & NS \\
\hline Myocardial infraction & $7(14,9 \%)$ & $56(16,8 \%)$ & NS \\
\hline Other & $3(6,4 \%)$ & $25(7,5 \%)$ & NS \\
\hline Fibrinolysis & $9(19,1 \%)$ & $42(12,7 \%)$ & NS \\
\hline
\end{tabular}

STEMI: ST Segment Persistant Elevation Myocardial Infraction

The initial symptomatology leading to hospitalization was chest echocardiography, the average ejection fraction was impaired pain in more than half of the cases (51.1\%). The main indication in the 21 elderly patients (58.3\%). Coronary angiography was was coronary syndromes with a persistant ST segment programmed in most of our patients (80.9\%), the right femoral elevation (STEMI) offset (29.8\%), followed by exercise angina approach was preferred (70.2\%). The average duration of the (23.4\%). Thrombolysis was performed in 9 patients (19.1\%). At procedure was 66.24 min.

Table 2: Coronarography data.

\begin{tabular}{|c|c|c|c|}
\hline Variables & $\begin{array}{c}\text { Patients over } 70 \text { Years old } N \\
(\%)\end{array}$ & $\begin{array}{c}\text { Patients under } 70 \text { Years old } N \\
(\%)\end{array}$ & $\mathbf{p}$ \\
\hline Planned angiography & $38(80,9 \%)$ & $303(91 \%)$ & NS \\
\hline Primary angioplasty & $1(2,1 \%)$ & $0(0 \%)$ & NS \\
\hline Delayed angioplasty & $8(17 \%)$ & $22(6,6 \%)$ & 0,006 \\
\hline Rescue angioplasty & $0(0 \%)$ & $5(1,5 \%)$ & 0,02 \\
\hline \multicolumn{4}{|c|}{ Procedure Pathways } \\
\hline Right radial artery & $23,4 \%$ & $31,5 \%$ & NS \\
\hline Right femoral artery & $70,2 \%$ & $62,2 \%$ & NS \\
\hline Left femoral artery & $0 \%$ & 0,6 & NS \\
\hline $\begin{array}{l}\text { Femoral artery after unsucceded } \\
\text { radial }\end{array}$ & $6,4 \%$ & $5,7 \%$ & NS \\
\hline Right dominant circulation & $30(63,8 \%)$ & $212(63,7 \%)$ & NS \\
\hline Bissector artery & $6(13,3 \%)$ & $32(10,1 \%)$ & NS \\
\hline Lesion $\geq 50 \%$ & $6(12,8 \%)$ & $21(6,4 \%)$ & 0,05 \\
\hline Lesion $\geq 50 \%$ proximal IVA & $21(44,6 \%)$ & $95(28,7 \%)$ & 0,02 \\
\hline Lesion $\geq 50 \%$ middle IVA & $12(25,5 \%)$ & $85(25,6 \%)$ & NS \\
\hline Lesion $\geq 50 \%$ distal IVA & $5(10,6 \%)$ & $22(6,6 \%)$ & NS \\
\hline $\begin{array}{c}\text { Lesion } \geq 50 \% \text { proximal circonflexe } \\
\text { artery }\end{array}$ & $14(29,8 \%)$ & $66(19,8 \%)$ & 0,0001 \\
\hline $\begin{array}{c}\text { Lesion } \geq 50 \% \text { distal circonflexe } \\
\text { artery }\end{array}$ & $9(19,4 \%)$ & $42(12,6 \%)$ & 0,05 \\
\hline $\begin{array}{c}\text { Lesion } \geq 50 \% \text { proximal right } \\
\text { coronary artery }\end{array}$ & $9(19,5 \%)$ & $54(16,3 \%)$ & NS \\
\hline $\begin{array}{l}\text { Lesion } \geq 50 \% \text { middle right } \\
\text { coronary artery }\end{array}$ & $19(41,3 \%)$ & $74(22,3 \%)$ & 0,05 \\
\hline $\begin{array}{c}\text { Lesion } \geq 50 \% \text { distal right coronary } \\
\text { artery }\end{array}$ & $6(13 \%)$ & $18(5,4 \%)$ & 0,02 \\
\hline Poximal IVA occlusion & $7(14,9 \%)$ & $29(8,8 \%)$ & 0,02 \\
\hline Proximal circonflexe occlusion & $10(21,3 \%)$ & $19(5,7 \%)$ & 0,000 \\
\hline Proximal right coronary occlusion & $2(4,3 \%)$ & $19(5,7 \%)$ & NS \\
\hline A lesion & $3(6,4 \%)$ & $30(9 \%)$ & NS \\
\hline B1B2Lesion & $19(40,4 \%)$ & $122(36,6 \%)$ & NS \\
\hline
\end{tabular}




\section{Journal of Cardiology \& Cardiovascular Therapy}

\begin{tabular}{|c|c|c|c|}
\hline C Lesion & $10(21 \%)$ & $50(15 \%)$ & NS \\
\hline Syntax Score $\geq 22$ & $4(8,5 \%)$ & $10(3 \%)$ & 0,001 \\
\hline Monotroncular lesion & $5(14,3 \%)$ & $105(46,9 \%)$ & 0,001 \\
\hline Bitroncular lesion & $17(48,6 \%)$ & $52(29,9 \%)$ & 0,001 \\
\hline Tritroncular lesion & $13(37,1 \%)$ & 8258 & 0,001 \\
\hline $\begin{array}{c}\text { DAP* Average cumulative (cGy. } \\
\text { cm2) }\end{array}$ & 8123 & 60,31 & 0,013 \\
\hline $\begin{array}{c}\text { Duration of the average procedure } \\
\text { (minutes) }\end{array}$ & 66,24 & NS \\
\hline
\end{tabular}

DAP: Dose Area Product

Table 3: Angioplasty data.

\begin{tabular}{|c|c|c|c|}
\hline Variables & $\begin{array}{c}\text { Patients over } 70 \text { Years Old N } \\
(\%)\end{array}$ & $\begin{array}{c}\text { Patients under } 70 \text { Years Old } N \\
(\%)\end{array}$ & $P$ value \\
\hline Angioplasty & $13(27,7 \%)$ & $77(23,1 \%)$ & NS \\
\hline Bare Stent & $7(14,9 \%)$ & $45(13,5 \%)$ & NS \\
\hline Active Stent & $8(17 \%)$ & $43(12,9 \%)$ & NS \\
\hline Succesfull angioplasty & $11(84,6 \%)$ & $73(94,8 \%)$ & NS \\
\hline \multicolumn{4}{|c|}{ Procedure's Complications } \\
\hline Coronary dissection & $1(2,1 \%)$ & $1(0,3 \%)$ & 0,00 \\
\hline Stroke & $0(0 \%)$ & $1(0,3 \%)$ & 0,00 \\
\hline Cardiogenic chock & $1(2,1 \%)$ & $0(0 \%)$ & 0,00 \\
\hline Death & $1(2,1 \%)$ & $0(0 \%)$ & 0,00 \\
\hline \multicolumn{4}{|c|}{ Procedure's Incidents } \\
\hline Angina & $3(6,4 \%)$ & $7(2,1 \%)$ & 0,09 \\
\hline Vagal reaction & $0(0 \%)$ & $5(1,5 \%)$ & NS \\
\hline Ventricular tachycardia & $0(0 \%)$ & $2(0,6 \%)$ & NS \\
\hline Other & $2(4,3 \%)$ & $2(0,6 \%)$ & NS \\
\hline
\end{tabular}

NS: Non Significant

At the angiography, a mean Syntax score was high in 4 patients $(8.5 \%)$ in subjects over 70 years, with diffuse coronary involvement both in the proximal but also distal segments; And with many more coronary occlusions within this population category (Table 2). Coronary angioplasty with stent placement was proposed in 13 patients (27.7\%), with almost as many active stents as bare stents and a good result and TIMI 3 flux in 84.6\% (Table 3). Very few incidents were reported during the procedure and very few complications related to the angioplasty procedure, including coronary dissection followed by the death of a patient.

\section{Discussion}

The prevalence of hospitalized patients for coronary angiography is increasing in sub-Saharan Africa in the space of a few decades (coronafric). This is justified by the epidemiological transition in the developing countries, marked by the emergence of cardiovascular diseases, which have already reached the weight of infectious and nutritional diseases [3]. Rapid urbanization of tropical regions, steady progression of cardiovascular risk factors and deficiencies in preventive medicine explain these observations [4].

The use of coronary angioplasty and angioplasty is less often planned in the elderly. This study has shown that coronary angiography can prove useful in elderly patients, and that it allows us to propose, in almost a third of cases, coronary angioplasty with a high success rate, correct feasibility, but at the cost of complications Smaller but slightly more frequent compared to young subjects. Patients over 70 years of age represented $12.7 \%$ of all coronary angiography patients Period of study. The main indications of coronary angiography in these subjects are acute coronary syndrome (ACS) and angina of effort. In the series of Kanwar et al. [5], 79\% of 90 years old patients with coronary artery disease had ACS, 56\% had unstable angina, and 23\% had MI. It is during ACS that the usefulness of the invasive approach seems the most obvious [6]. However, patients aged over 70 years proposed for coronary angiography are generally very selected. 
In the work of Bagnall et al. [7] based on the ACS and GRACE registers, it was noted that the increase in the rate of invasive procedures over time benefited patients aged less than 65 years even though there was a significant increase in the use of invasive procedures Coronary angiography and angioplasty in elderly subjects. In our series, the femoral pathway was the most used for coronary angiography and coronary angioplasty. The difficulties of retrograde catheterization were more frequent in the radial than in the femoral, and sometimes led to a conversion to the femoral tract.

To the best of our knowledge, there are no studies comparing the radial to the femoral pathway in black African elderly subjects. In a randomized study comparing the two pathways in patients over 75 years of age, the duration of the procedures was not different and the conversion rate of the radial pathway to the femoral pathway was $9 \%$ [8]. In almost all published series, the femoral pathway was exclusive [6] or predominant $(>80 \%)[5$, $9-11]$ as was the case in our series. Only a French study reports the majority use of the radial pathway in a population of more than 85 years, mainly male [12]. Recent recommendations consistently suggest the radial pathway even in elderly subjects [13], at the cost of vascular loop difficulties, in order to reduce the frequent hemorrhagic complications at this age in a risky pharmacological environment. However, the radial approach is growing rapidly in our center, particularly with the arrival of young angioplastic surgeons trained in French centers.

In angiography, our study shows that approximately half of the patients have at least two or more coronary lesions, more than one-third had three coronary lesions, and also more severe occlusive lesions in subjects over 70 years old showing the severity of coronary involvement. This is found in the approach study [14], where $45 \%$ of subjects aged less than 80 years have bi-troncular lesions. This proportion is approximately $60 \%$ for patients over 80 years old.

Proximal truncus involvement was more predominant in subjects over 70 years of age, and reached the downstream bed, showing diffuse coronary involvement of these elderly subjects. On the other hand, this anatomical severity does not translate into the level of management by angioplasty or the management remains mainly minimalist with less systematic angioplasty of all significant coronary lesions.

However, our center is one of the first centers of cardiac catheterization in West Africa, which began our activities recently in 2013 and we were limited by the availability of the stents in particular active but also by their cost in a low-income African population. The cardiac clinic at the Aristide Le Dantec University Hospital in Dakar is a small center, but the first results of angioplasty are very encouraging. The angioplasty in our series was mainly performed by an active stent (nearly $17 \%$ ), the proportion of bare stents is about $14.9 \%$, it remains lower than that found in the literature. In the PAPI registry, 35\% of patients between the ages of 75 and 80 years had an active stent, $21 \%$ in patients between the ages of 80 and 85 , and $13 \%$ in patients aged over 85 years.

In the ACS sub-group of the PAPI registry, $23 \%$ of patients had an active stent. Overall in the registers, the percentage of active stents in the elderly is reduced compared to younger patients, given the fragility of the patients, the high anemia and renal insufficiency and the greater risk of hemorrhagic risk. However, age alone should not be an obstacle to the placement of an active stent. It is a bundle of arguments with comorbidities and an assessment of the hemorrhagic risk of the patient that should lead to the decision. An invasive strategy, therefore, has a net benefit in this population category.

In addition, our study shows that elderly patients treated invasively do not have more complications and procedural incidents than young people. Thus, if coronary angiography is indicated, it is technically feasible in the elderly and does not lead to more complications, in particular hemorrhagic complications than exclusive medical treatment [15].

In the same work, the benefit on mortality when using invasive procedures appears to be clearer in patients over 75 years of age. This better benefit in the elderly has already been shown in the study Tactics TIMI 18 [16]. A recent study of acute coronary syndrome in the elderly, based on the ACOS registry [17], showed that hospital mortality was $12.5 \%$ in the medical treatment group, compared with $6 \%$ in the group that benefited from an invasive strategy. An invasive strategy therefore has a net benefit in this population category, yet it benefits less from this strategy, probably because of an over-estimation of the haemorrhagic risk and an underestimation of the ischemic risk.

\section{Conclusion}

Our study shows the severity and spread of coronary disease in black African subjects over 70 years old. Their management should not differ from the younger one in terms of invasive strategy and use of angioplasty even in our low-income countries recently equipped with cardiac catheterization room. Coronary angioplasty is feasible with a high success rate, at the cost of an acceptable level of local and general complications. The radial pathway is preferred because it is likely to limit hemorrhagic complications at the point of frequent punctures at this age. The extreme age of patients is not a contraindication per se to invasive strategy.

\section{References}

1. Fox KAA, Dabbous OH, Goldberg RJ, Pieper KS, Eagle KA, et al. (2006) Prediction of risk of death and myocardial infarction in the six months after presentation with acute coronary syndrome: prospective multinational observational study (GRACE). BMJ 333(7578): 1091.

2. Ryan TJ, Faxon DP, Gunnar RM, Kennedy JW, King SB, et al. (1988) Guidelines for percutaneous transluminal coronary angioplasty. A report of the American College of Cardiology/American Heart Association Task Force on Assessment of Diagnostic and Therapeutic 
Cardiovascular Procedures (Subcommittee on Percutaneous Transluminal Coronary Angioplasty). Circulation 78(2): 486-502.

3. Mendis S, Lindholm LH, Mancia G, Whitworth J, Alderman M, et al. (2007) World Health Organization (WHO) and International Society of Hypertension (ISH) risk prediction charts: assessment of cardiovascular risk for prevention and control of cardiovascular disease in low and middle-income countries. J Hypertens 25(8): 15781582 .

4. Touze JE (2007) Les maladies cardiovasculaires et la transition épidémiologique du monde tropical. Med Trop 67(6): 541-542.

5. Kanwar M, Aleksonis D, Kolluru A, Awasthi A, Rosman HS (2010) Safety and efficacy of cardiac catheterization in nonagenarians. J Clin Outcomes Management 17(7): 309-312.

6. Parikh R, Chennareddy S, Debari V, Hamdan A, Konlian D, et al. (2009) Percutaneous coronary interventions in nonagenarians: in-hospital mortality and outcome at one-year follow-up. Clin Cardiol 32(12): E16-E21.

7. Bagnall AJ, Goodman SG, Fox KA, Yan RT, Gore JM, et al. (2009) Influence of age on use of cardiac catheterization and associated outcomes in patients with non-ST-elevation acute coronary syndromes. Am J Cardiol 103(11): 1530-1536.

8. Achenbach S, Ropers D, Kallert L, Turan N, Krähner R, et al. (2008) Transradial versus transfemoral approach for coronary angiography and intervention in patients above 75 years of age. Catheter Cardiovasc Interv 72(5): 629-635.

9. Wu YJ, Hou CJY, Chou YS (2004) Percutaneous coronary intervention in nonagenarians. Acta Cardiol Sin 20: 73-82.

10. Koutouzis M, Grip L, Matejka G, Albertsson P (2010) Primary percutaneous coronary interventions in nonagenarians. Clin Cardiol 33(3): 157-161.
11. Rigattieri S, Cera M, Sciahbasi A, Di Russo C, Fedele S, et al. (2013) Primary percutaneous coronary intervention in nonagenarians: sixmonth outcomes from a single-center registry. J Invasive Cardiol 25(5): 242-245.

12. Deman AL, Schiano P, Chenilleau MC, Monsegu J (2010) Les patients très âgés sont-ils de bons candidatsà l'angioplastie coronaire? Une étude rétrospective monocentrique. Ann Cardiol Angeiol 59(5): 278284.

13. Biondi Zoccai G, Abbate A, D’Ascenzo F, Presutti D, Peruzzi M, et al. (2013) Percutaneous coronary intervention in nonagenarians: pros and cons. J Geriatr Cardiol 10(1): 82-90.

14. Graham MM, Ghali WA, Faris PD, Galbraith PD, Norris CM, et al. (2002) Survival after coronary revascularization in the elderly. Circulation 105(20): 2378-2384.

15. Rittger H, Schnupp S, Sinha AM, Breithardt OA, Schmidt M, et al. (2012) Predictors of treatment in acute coronary syndromes in the elderly: impact on decision making and clinical outcome after interventional versus conservative treatment. Catheter Cardiovasc Interv 80(5): 735743.

16. Cannon CP, Weintraub WS, Demopoulos LA, Vicari R, Frey MJ, et al. (2001) Comparison of early invasive and conservative strategies in patients with unstable coronary syndromes treated with the glycoprotein IIb/IIIa inhibitor tirofiban. N Engl J Med 344(25): 18791887.

17. Bauer T, Koeth O, Junger C, Heer T, Wienbergen H, et al. (2007) Effect of an invasive strategy on in-hospital outcome in elderly patients with non- ST-elevation myocardial infarction. Eur Heart J 28(23): 28732878.

\section{Your next submission with Juniper Publishers} will reach you the below assets

- Quality Editorial service

- Swift Peer Review

- Reprints availability

- E-prints Service

- Manuscript Podcast for convenient understanding

- Global attainment for your research

- Manuscript accessibility in different formats

( Pdf, E-pub, Full Text, Audio)

- Unceasing customer service

Track the below URL for one-step submission https://juniperpublishers.com/online-submission.php 